\title{
Return to Work and Painkiller Medication after Rehabilitation for Subacute Back Conditions
}

\author{
-A 2-Year Follow-Up
Annalisa Gison ", Loredana Bruti, Valentina Dall'armi, Enzo Palma, Salvatore Giaquinto IRCCS Rehabilitation Institute San Raffaele Pisana, Rome, Italy Email: "annalisa.gison@sanraffaele.it

Received May $1^{\text {st }}, 2012$; revised March 24 $4^{\text {th }}, 2013$; accepted April 2 $2^{\text {nd }}, 2013$

\begin{abstract}
Copyright (C) 2013 Annalisa Gison et al. This is an open access article distributed under the Creative Commons Attribution License, which permits unrestricted use, distribution, and reproduction in any medium, provided the original work is properly cited.
\end{abstract}

\begin{abstract}
The study was aimed at evaluating the outcome after 2 years in a population of outpatients suffering from Low Back Pain (LBP) who were treated with a multi-disciplinary approach. The end-points were: 1) the rate of return to work (RTW); 2) the frequency of painkiller medication; 3) the frequency of unavoidable surgical operation; 4 ) the rate of relapses. Eighty consecutive subjects ( $75 \%$ women) were enrolled. They were referred by general physicians and completed the rehabilitation program at our centre. We followed an open, prospective design. The main results were: RTW: $92.5 \%$ positive cases; $7.5 \%$ failure. Job cohort settlement: $93.1 \%$ the same; $6.9 \%$ change. Time interval between discharge and RTW: $76.8 \%$ few days after discharge. Painkillers: At follow-up 46 participants (57.5\%) could stop the medication. Surgical operations: At admission 39 participants presented with lumbar root involvement (48.7\%). Only 4 of them had a surgical intervention (10.2\%). In a third of cases of the all sample relapses did not occur. In conclusion, a multi-disciplinary model of intervention led to a high rate of RTW, a reduction of painkiller medication, a low rate of surgical interventions and of relapses as well. Further controlled studies are warranted for assessing the cost/benefit ratio. The clear prevalence of LBP in women recommends measures of preventing Medicine.
\end{abstract}

Keywords: Low Back Pain; Postural Rehabilitation; Work

\section{Introduction}

Low back pain (LBP) affects approximately $80 \%$ of adults at some time in life (Deyo, 1996) and occurs in all ages (Hartvigsen, 2008; Jensen, 2011). Observations indicate an annual prevalence of symptoms in $50 \%$ of the adult working age and $15 \%-20 \%$ of these are addressed in the care of the occupational physician. LBP occurs most often between 30 and 50 years of age. For people under 45 years of age, LBP is the most common cause of disability. Pain and rigidity are the main symptoms. These ones account for disability and lack of participation. LBP is considered as a benign and self-limiting condition. Yet, recurrence happens frequently with a small risk of developing into a chronic condition (Croft, 1998). Long-term sick leave is common among primary care patients with musculoskeletal pain. Physical functioning and return to work (RTW) after one year are poor (Atroshi, 2002).

Despite the post-industrial economy is less and less heavy for the worker for increased automation of the production cycle and medicine has developed much capacity for diagnosis and treatment, the inability to work caused by LBP increases constantly. Despite billions being spent on various diagnostic and treatment approaches, the prevalence and disability related to LBP has continued to increase (Deyo, 2009). LBP has an

${ }^{*}$ Corresponding author. enormous impact on individuals, families, communities, governments and businesses throughout the world (Hoy, 2010). In Italy where this research has been carried out $8.2 \%$ of the Italian population in 1999 suffered from LBP (ISTAT, 1999) and $13.5 \%$ reported regular use of analgesics or nonsteroidal anti-inflammatory drugs (NSAIDs) in the two weeks preceding the onset of LBP (Juniper, 2009). The economic burden of LBP is of considerable relevance. In USA, the costs are estimated to be $\$ 50$ billion per year (Frymoyer, 2010). The cost of LBP in The Netherlands in the nineties was estimated to be $1.7 \%$ of gross national product, $93 \%$ of the cost was due to sick leave and disability (Van Tulder, 1995). The annual direct costs of LBP in Germany are estimated over $€ 7000$ per person. Sick leave at work accounted for $75 \%$ of the total cost per patient for LBP (Juniper, 2009). Neverthe- less, other authors support the concept that treating LBP is cost- effective (Moffett, 1999).

The specific cause of LBP is unidentified in many subjects in spite of refined diagnostic tools. An estimated $85 \%$ of subjects have a diagnosis of unspecified LBP, which is interpreted as a multi-factorial condition (Gore, 2011). Over 100 risk factors have been identified (Cole, 2003). They are related to musculoskeletal problems due to mechanical, inflammatory, degenerative, infective or neoplastic causes. Early evidence also points to a genetic predisposition to lumbar disk disease (Paassilta, 2001). In recent years there has been a movement away 
from the biomedical model for understanding the LBP experience toward a bio psychosocial model (Jones, 2002; Waddell, 2004). That is, LBP has increasingly been recognized as involving somatic, neurophysiologic and psychological factors that all contribute to the clinical picture clinicians encounter (Deyo, 2009). Many environmental and personal factors influence the onset and course of low back pain. Other commonly reported risk factors include low educational status, stress, anxiety, depression, job dissatisfaction, low levels of social support in the workplace and whole-body vibration (Hoy, 2010). Although various occupational physical activities are suspected of contributing to LBP, causal relationships have not been confirmed, complicating adjudication of work injuries, RTW instructions and preventive efforts. This may be related to insufficient or poor quality scientific literature, as well as the difficulty of establishing causation of LBP. These population-level findings do not preclude the possibility that individuals may attribute their LBP to specific occupational physical activities (Heneewer, 2011).

According to back school there is moderate evidence suggesting that the treatment is beneficial in an occupational setting, in the short and intermediate-term, compared to other physical intervention, placebo or waiting list controls (Heymans, 2005). Exercise therapy appears to be slightly effective at decreasing pain and improving function. In sub-acute LBP there is some evidence that a graded activity program improves sick leave, though evidence for other types of exercise is unclear (Hayden, 2005). However, there is a poor correlation between the high number of physical interventions, which can be of potential benefit, and the Evidence Based Medicine. First of all, a number of articles find no evidence of their efficacy for acute LBP (Hayden, 2005; Schonstein, 2003). Meta-analytic studies provide a weak evidence of effectiveness. Most treatments for chronic LBP provide poor results and the benefits can be just transient (Cohen, 2008). In general, randomized controlled trials (RCT) concerning RTW have failed to demonstrate significant treatment effects for long-lasting musculoskeletal pain, and most treatments have not been economically beneficial (Haldorsen, 2002). Recent studies suggest that a psychosocial intervention can lead to meaningful reductions in psychosocial risk factors for pain and disability and may contribute to more positive rehabilitation outcomes (Sullivan, 2010; Stapelfeldt, 2011; Middelkoop, 2011; Zampolini, 2007).

\section{Research Question and Aim}

The present article summarizes the experience obtained from a population of outpatients suffering from LBP and referred by general physicians. A multidisciplinary intervention was applied (Giaquinto, 2010). The study was mainly aimed at evaluating: 1) the rate of RTW and its interval; 2) the length of medication usage; 3 ) the rate of surgical interventions on entrapped roots; 4) the rate of relapses.

\section{Methods}

\section{Participants}

Study design: open prospective study. The Ethical Committee approved the study. The participants gave the informed consent. Eighty consecutive subjects suffering from subacute LBP were enrolled after selection. Sixty participants were women (75\%). The mean age was 48 years (sd 9.1). They had
12 years of education (sd 4.1). The group included 36 whiteand 24 blue collars, 14 housewives, 4 retired and 2 unemployed persons. Full-time job occurred in $67.2 \%$ of cases; $29.3 \%$ part time; $3.4 \%$ timeless job. They were referred by general physicians operating in the district and completed the rehabilitation program. The inclusion spanned over 16 months. The range of disturbance duration at program initiation was more than four weeks but less than three months. A physician and a physiotherapist provided detailed assessment of the participants' history, pain, and physical check (including posture). Neuroimaging at lumbar segment (either CT-scan or MRI) and EMG were performed only in those participants complaining of irradiation or presenting with clinical worsening.

\section{Inclusion Criteria}

Subjects suffering from subacute LBP were enrolled.

\section{Exclusion Criteria}

Cognitive and sensory impairment, lack of compliance, neurological diseases, multiple myeloma or malignant tumours, spondilytis, ankylosis, Paget disease, severe comorbilities and malingering.

\section{Measures}

Socio-demographic data, job description, vitality indexes (driving, sport, dance), medication usage and relapses were recorded. The following scales were administered:

1) Mini Mental Scale for cognitive function (Folstein, 1975). The cut-off of 24/30 was applied;

2) Cumulative Illness Rating Scale (Linn, 1975), which is an ordinal scale, where each item can be scored from $1=$ normal to 5 life-threatening situation. Participants scoring above 3 in any item and those having a Comorbidity Index above 3 were not included;

3) Oswestry Low Back Pain Disability Questionnaire (Fairbank, 2000). This questionnaire has been designed to give the physical therapist information about back pain and the ability to manage in everyday life. Index Score $=[$ Sum of all statements selected dived by the numbers of selections with a statement selected $\times 5$ )] $\times 100$. A recent survey recommends the scale (Frost, 2008);

4) Trunk Control scale $(0=$ no control; $100=$ normal $)$ (Franchignoni, 1997);

5) Motricity Index $(0=$ paralysis $100=$ normal $)$ (Demeurisse, 1980);

6) Visual-Analogue Scales was finally used to record pain intensity (Huskisson, 1976). The scale ranges from 0 (no distress) to 10 (unbearable distress).

Information on whether patients returned to work after the rehabilitation (RTW), LBP disability and pain intensity were also recorded after 2 years from discharge.

\section{Interventions}

The rationale of Interventions has been already presented by us in details (Giaquinto, 2010).

A short description is presented herewith.

The program for the present study included 3 hours of rehabilitative treatment three times a week, for 16 sessions. A comprehensive bio-psycho-social approach was followed. The pro- 
gram included:

1) Group therapy. After a warm-up a group therapy up to 8 participants performed free and progressively loaded exercises of trunk, 1 minute each, involved both abdominal, para-vertebral and pelvic floor muscles under the supervision of a physiccal therapist. The session also included a light stretching of stiff muscles: in other words, a biological girdle, for reducing the pressure upon the lumbar disks. A mirror provided visual feedback. The intensity of the exercises was progressive over the 16 treatments with participants being invited to improve their own performance without any competition. Short relaxation sessions took place every 10 minutes, i.e. every block of 10 exercises.

2) Global postural retraining according to a motor control approach was developed on the principle that participants with LBP have a lack of control of the trunk muscles. A motor learning approach retrained the optimal control and coordination of the spine. The intervention involved the training of preactivation of the deep trunk muscles, followed by more complex static, dynamic, and functional tasks. Again, a tutorial approach helped the proper contraction of superficial and deep trunk muscles for an integrated activation. The difficulty of the tasks was increased over time. The treatment was individually tailored and lasted about 45 minutes.

3) Counselling and emotional support. A physician provided participants with information on anatomy and physiology of spine in order to improve awareness, perceived health and perceived ability to perform physical tasks. A psychological approach prompted encouragement of skill acquisition, use of pacing, setting progressive goals, confidence of progress, and positive reinforcement of progress. The psychologist fostered expectations, fear-avoidance, and inner locus of control. Indeed, reassuring participants was supposed to ameliorate favourable subjective evaluation. Participants were encouraged to exercise at home at least once a day, to be active and to incorporate exercise into their daily activity. Leisure activities were recommended. Encouraging participants to engage in problem solving to deal with daily difficulties was supposed self-reliance.

4) Description of the workplace. In recent years there is an increasing discussion of internal and external barriers and facilitators about RTW in patients suffering from chronic LBP as introduced by ICF. In fact recent studies identify barriers such as despair, lack of supervisory support in workplace system, waiting period and long during medicalization in Healthcare System. Always these studies identify some facilitators such as tailored exercises and thorough protocol communication process. A workplace visit is recommended because the treatment effectiveness increases (Karjalainen, 2003).

When a workplace visit was difficult, information about self- assessed work ability, and self-predicted absence status was collected. Indeed, the information can be predictor of time until RTW in participants with LBP certified as sick who attend a back disorder outpatient clinic (Reiso, 2003).

After 2 years the participants were invited to a new complete check.

\section{Statistics}

Frequencies of socio-demographic information and summary statistics (n, mean, standard deviation (sd), minimum, 25th percentile, median, 75 th percentile and maximum) were calculated. Correlations were also estimated between all parameters measured on a continuous scale. The long-term effect of the rehabilitation on the disability and on the pain intensity was tested by means of a linear regression, so as to estimate the importance of all covariate information (age, gender, education, type of job, RTW) and the presence of gender-by-age and gender-by-RTW interactions. All analyses were adjusted for baseline scores. Motricity Index and Trunk Control were not included in the model.

\section{Results}

\section{Descriptive Statistics}

The sample comprised 60 females $(75 \%)$ and $20(25 \%)$ males, for a total of 80 participants all suffering from LBP. Their mean age was $47.5 \mathrm{yr}$ (sd 9.1, range 27 - 72). The mean education was $11.8 \mathrm{yr}$ (sd 4.1, range 3 - 26). Most patients lived with their spouse $(67.5 \%)$ and $11.2 \%$ lived alone. The majority was married $(61.2 \%)$, a good proportion were single $(23.7 \%)$ and some declared to be separated or divorced (12.5\%).

Almost all participants returned to work $(92.5 \%)$. The percentage included housewives, retired and 2 unemployed persons. In these cases RTW meant housekeeping, gardening, shopping, pet care. Job settlement was the same in $93.1 \%$; changed in $6.9 \%$ (formerly jobs: 1 full time warehouse-keeper, 1 part time nurse, 1 part time servant; 1 part time gym trainer and 1 truck driver).

Four subjects scored 0 on disability at the follow-up visit and 16 scored zero on the VAS, declaring a complete lack of distress.

The mean percentage of disability was reduced by approximately $15 \%$ by the follow-up visit and an improvement was also observed for the intensity of pain, which decreased by 3 points by the last visit. All relevant summary statistics are provided in Table 1.

Table 1.

Summary statistics for disability and pain intensity.

\begin{tabular}{|c|c|c|c|c|c|c|}
\hline & & Minimum & 25th Percentile & 50th Percentile & 75th Percentile & Maximum \\
\hline \multirow{2}{*}{ Baseline } & Disability & 18.00 & 22.00 & 32.00 & 40.00 & 60.00 \\
\hline & Pain Intensity & 5.00 & 6.00 & 7.00 & 8.00 & 10.00 \\
\hline \multirow{2}{*}{ Follow-Up } & Disability & 0.00 & 10.00 & 17.00 & 26.00 & 60.00 \\
\hline & Pain Intensity & 0.00 & 1.00 & 4.00 & 6.00 & 10.00 \\
\hline \multirow{2}{*}{ Difference from Baseline } & Disability & -32.00 & -20.00 & -14.00 & -8.00 & 0.00 \\
\hline & Pain Intensity & -9.00 & -5.00 & -3.00 & -1.00 & 4.00 \\
\hline
\end{tabular}


A strong positive correlation emerged between 1) the change in pain intensity and the baseline level of disability $(r=0.30, p=$ $0.01), 2)$ the baseline pain intensity and the baseline disability level $(\mathrm{r}=0.61, p<0.01)$. Moreover, a strong negative correlation was found between 1) the change in disability and the baseline pain intensity $(\mathrm{r}=-0.30, p=0.01)$; 2$)$ the baseline disability and the number of years of education $(\mathrm{r}=-0.30, p=$ $0.01)$; 3) the baseline pain intensity and the number of years of education $(\mathrm{r}=-0.23, p=0.04)$; 4$)$ the age and the number of years of education $(\mathrm{r}=-0.39, p<0.01)$. The analysis of correlation output is provided in Table 2.

The fitted model (Table 3) explained 68\% of the total variability in the data. Disability level significantly changed from pre- to post-rehabilitation (time effect: $p<0.01$ ). No other considered covariate was significantly associated to the disability level, nor an interaction between gender and age or RTW emerged. The $p$-values refer to the effect of each covariate adjusted for the presence of all other covariates. Statistical significance: $p<0.05$ (Table 3).

The fitted model explained $40 \%$ of the total variability in the data (Table 4). Pain intensity changed significantly from pre- to post-rehabilitation (time effect: $p<0.01$ ). No other considered covariate was significantly associated to the pain intensity, nor an interaction between gender and age or RTW emerged. The $p$-values refer to the effect of each covariate adjusted for the presence of all other covariates. Statistical significance: $p<$ 0.05 .

Work was stopped during treatment. The mean time interval between discharge and RTW was 6 days after discharge (76.8\%). Longer intervals occurred as 2 - 3 months (a warehouse-keeper, a clerk); 6 months (a graphic artist); 1 year (a truck driver).

Summing up, strong evidence was found in favour of an improvement of disability and pain intensity, whereas no other main effects or interactions emerged.

\section{Pain Killers}

The most frequently used painkillers were ASA and diclofenac: At follow-up 46 participants $(57.5 \%)$ could stop the medication and took no painkillers at all. By contrast, 20 participants $(25 \%)$ maintained medication. Seventy percent of them were women. However, 3 participants reported a lesser usage than before. The free interval after discharge had a median value of 2 months (range 0 - 12). Finally, 14 participants did not use painkillers either before the admission or after discharge. The frequency of use was variable in consumers, generally every 2 weeks. Daily medication was found in $2.5 \%$ of cases.

\section{Surgical Operations}

At admission 39 participants presented with signs of compressed spinal root, that was confirmed by EMG (48.7\%). Only 4 of them had a surgical intervention $(10.2 \%$ of the sub-group, $5 \%$ of the total sample). A participant was operated twice. The conservative therapy failed in one full-time school caretaker, 1 full time janitor, 1 full time clerk, 1 full time truck driver.

\section{Relapses}

Moderate relapses occurred in 53.7\% (work and ADL generally continued); $12.5 \%$ very moderate; $33.7 \%$ never. The relapse interval was $30.5 \%$ after 1 year; $48.1 \%$ between 2 and 8 months; $11.7 \%$ after 1 month; $5.8 \%$ after 2 - 3 weeks. Steady pain in $3.9 \%$ of cases. When relapses occurred, the participants used painkillers and did not return to the rehabilitation centre.

\section{Modified Environment}

No modification occurred in $73.7 \%$; of cases. Modified shoes, bed, pillow and mattress occurred in the other cases.

\section{Radiological Examinations after Discharge}

There was no examination in $68.8 \%$ of cases, 1 time in $23.7 \%, 2$ times in $7.5 \%$.

\section{Sport}

No sport was found in $66.2 \%$ of cases. By contrast swim-

Table 2.

Correlations between baseline disability and pain intensity, difference from baseline disability and pain intensity, age and education.

\begin{tabular}{|c|c|c|c|c|c|c|}
\hline & Disability & Pain Intensity & Disability Baseline & Pain Intensity Baseline & Age & Education \\
\hline Difference from Baseline Disability & 1.00 & & & & & \\
\hline \multirow{2}{*}{ Difference from Baseline Pain Intensity } & 0.15 & 1.00 & & & & \\
\hline & 0.18 & & & & & \\
\hline \multirow{2}{*}{ Disability Baseline } & -0.22 & 0.30 & 1.00 & & & \\
\hline & 0.05 & 0.01 & & & & \\
\hline \multirow{2}{*}{ Pain Intensity Baseline } & -0.30 & -0.02 & 0.61 & 1.00 & & \\
\hline & 0.01 & 0.84 & $<0.01$ & & & \\
\hline \multirow{2}{*}{ Age } & 0.07 & 0.01 & 0.10 & -0.03 & 1.00 & \\
\hline & 0.56 & 0.91 & 0.37 & 0.78 & & \\
\hline \multirow{2}{*}{ Education } & 0.06 & -0.11 & -0.30 & -0.23 & -0.39 & 1.00 \\
\hline & 0.58 & 0.32 & 0.01 & 0.04 & $<0.01$ & \\
\hline
\end{tabular}

Note: Bold Characters: statistical significance. 
Table 3.

Selected output from the linear regression analysis of the difference from baseline disability level.

\begin{tabular}{cccc}
\hline & df & F & $p$ \\
\hline Time & 1 & 292.51 & $<0.01$ \\
Gender & 1 & 0.11 & 0.74 \\
Age & 1 & 0.14 & 0.71 \\
Education & 1 & 0.92 & 0.34 \\
Job & 4 & 1.82 & 0.13 \\
RTW & 1 & 0.00 & 0.95 \\
Disability Baseline & 1 & 3.78 & 0.05 \\
Gender $\times$ Age & 1 & 0.04 & 0.84 \\
Gender $\times$ RTW & 1 & 0.40 & 0.53 \\
$\mathrm{~N}$ & 159 & $\mathrm{R} \wedge 2$ & 0.68 \\
Variance & 5.44 & $\mathrm{R} 2$ Adjusted & 0.65 \\
\hline
\end{tabular}

Table 4.

Selected output from the linear regression analysis of the difference from baseline pain intensity.

\begin{tabular}{cccc}
\hline & df & F & $p$ \\
\hline Time & 1 & 88.97 & $<0.01$ \\
Gender & 1 & 1.31 & 0.25 \\
Age & 1 & 0.36 & 0.55 \\
Education & 1 & 3.94 & 0.05 \\
Job & 4 & 0.72 & 0.58 \\
RTW & 1 & 0.50 & 0.48 \\
Pain Intensity Baseline & 1 & 0.06 & 0.80 \\
Gender $\times$ Age & 1 & 1.17 & 0.28 \\
Gender $\times$ RTW & 1 & 0.41 & 0.52 \\
$\mathrm{~N}$ & 160 & $\mathrm{R}^{\wedge} 2$ & 0.40 \\
Variance & 2.02 & $\mathrm{R}^{\wedge} 2$ Adjusted & 0.35 \\
\hline
\end{tabular}

ming, gym, racing, tennis; bike and motorbike were reported by the other participants.

\section{Driving Vehicles}

The majority $(83.8 \%)$ of participants drove a car or a motorbike. No driving occurred in $16.2 \%$.

\section{VAS and Oswestry Disability Rating at Follow-Up}

The questionnaires at the 2-year follow-up gave the following results:

1) RTW group: "Last week" median VAS: 3; "Now": 3. Me- dian Oswestry disability rating 16.

2) Failed RTW group: "Last week" median VAS: 5; "Now": 5. Median Oswestry disability rating 36.

\section{Discussion}

The study has a cohort prospective design. The lack of a control group places several limitations for concluding that the multidisciplinary intervention model is cost-effective. It is easier to describe RCT than to prescribe in a rehabilitation setting. At least in our settlement, outpatients suffering from LPB communicate among them and share opinions about their painful experience. If the $\mathrm{A}$ treatment were more effective than the $\mathrm{B}$ treatment, the patients belonging to the latter group would call for the shift to the A group. The same may happen if we had matched a treatment against a shorter version of itself. For example, the psychological support was very appreciated by the participants. Ethically, any shift to the more favourable treatment can not be denied. The cross-over of participants would clearly reduce the strength of recruitment.

Nevertheless the follow-up at 2 years of participants suffering from sub-acute and non-specific LBP provided information of general interest. We could exploit the results of the last decade of physical therapy, being several of them obtained from RCT studies including housewives. RTW occurred in a very high percentage of our participants. Several factors account for the favourable results, although the multidisciplinary design does not allow the weight of each single intervention.

1) Early multimodal rehabilitation is important (Westman, 2006). Participants who are referred earlier have a more likely RTW (Ehrmann-Feldman, 1996). The duration of the current episode is also a stable predictor of prognosis in LBP (Bekkering, 2005).

2) General exercise followed by Motor Therapy that was successfully applied in controlled studies (O'Sullivan, 1997; Macedo, 2009). It was determined for each exercise how physically active the participants were, how intense LBP was, and was the ability of the participant to perform the exercises. Participants were then taught the exercises and advised of the intensity at which they had to exercise. Training included the recruitment of deep muscles of the spine and reduced activity of other muscles. The exercises aimed at improving function of specific trunk muscles thought to control inter-segmental movement of the spine.

3) Counselling. Basic knowledge of anatomy and physiology of spine was appreciated by participants at the first phase of counselling. We also exploited suggestions from other studies, such as perceived ability to work again, and activity advice. A physiatrist provided the proper advice to avoid postural errors at work and indicated specific movements according to situations.

4) Psychological support. The fear of no-recovery should be actively overcome (Karjalainen, 2004; Dionne, 2007). Reassurance, counselling are effective in many cases of acute, nonspecific LBP, which resolve in a positive way. Psycho-logical support is an important step in our model. It reinforces the socalled internal Locus of Control (LOC). Individuals with internal LOC expect to manage the outcome, while individuals with external LOC expect that other, external factors affect outcome (Selander, 2005). The expectancy might predict the future activity. In alleviating pain, the intervention was most effective among the participants with a high-perceived risk of failure 
(Karjalainen, 2003; Karjalainen, 2004). A meta-analysis indicates that expectation is predictive of work outcome (Iles, 2008). Benefit was observed in those candidates who had high scores on fear and low scores on function. The exposure treatment is based on the pain-related fear model and as a result improvements in function are expected to be related to changes in fear and cognitions. Our linear Regression Analysis of the change of Pain Intensity over time gave importance to Education, whereas this variable was not relevant when disability was considered. Graded exposure in vivo is a new, specific, cognitive-behavioural treatment that is especially tailored to patients with high levels of pain-related fear. Overall exposure has moderate effects on function, fear and pain intensity and should go in parallel with physical therapy (Linton, 2008). On this basis we exploited the exposure and included work situations with specific movements.

Although it is unsafe to compare data from different socioeconomical backgrounds, a survey in Norway found that about $35 \%$ of patients returned to work after 1 month, $70 \%$ had returned after 3 months, and $85 \%$ had returned after 6 months. (Hagen, 1998). Intensive reconditioning programs for LBP participants had the following effects on RTW status after 1 year. On the basis of 109 questionnaires 57 patients $(52.3 \%)$ were working, $39(35.8 \%)$ full time and $18(16.5 \%)$ part time. The remaining 52 patients were on disability leave. All participants had followed a physical reconditioning program 12 months earlier. The program included $6 \mathrm{~h}$ of physical and occupational therapy each day, $5 \mathrm{~d}$ a week for 3 weeks (Casso, 2004). Psychological support was not considered in those studies. The model that we applied prompted RTW in $92.5 \%$ of cases at retest.

Strangely indeed, medication usage is rarely discussed in articles on LBP, although pain-related medications are widely prescribed (Gore, 2011). Several participants still experienced some pain at 12 months follow-up (Bekkering, 2005). RTW and no medication were found in another study (Iles, 2008). During pain episodes, participants had significantly greater disability and higher medication use (McGorry, 2000). In our sample $66 \%$ of participants regularly used painkillers at admission. By contrast, $75 \%$ of participants had completely stopped medication at follow-up. The medication withdrawal turns out in both a financial saving and a removal of risk factors for gastro-intestinal diseases.

Gender is an important issue in LBP. In our study women accounted for $75 \%$ of the sample but linear regression failed to indicate a significant relationship between outcome and gender. In a very large sample in Norway (Hagen, 1998) the estimated overall 1 -year incidence was $2.2 \%$. It was significantly higher for women $(2.7 \%)$ than for men $(1.9 \%)$. Lifting activities in house holding, heels and pregnancy are significant risk factors. Indeed, an increased risk of relapse exists in case of jobs requiring lifting, pulling or pushing objects $>25 \mathrm{lbs}$. Prolonged periods of standing or walking may have the same effect. Risks are, in general, greater in women, for a first ever episode of LBP (Heymans, 2005; Macfarlane, 1997). On the other hand, differences of outcome after therapy still exist. A full-time behavioural medicine program was particularly effective in females, whereas rehabilitating men had no significant effect on either health or costs (Jensen, 2005). In men significantly better results for full RTW were found for light multidisciplinary treatment compared with treatment as usual, but no differences were found between extensive multidisciplinary treatment and treatment as usual. No significant differences between any of multidisciplinary treatment programs and the controls were found for women (Skouen, 2002). Other studies found no gender-dependent length of sickness leave (Indahl, 1995). In women negative predictor was also the unsatisfaction with their physician. In men negative outcome were connected with high pain levels, decreasing age, cigarette smoking, low self-perceived health status, pain in the thoracic area and previous surgical intervention on spinal roots, lack of fiscal compensation and perception of their under-qualified or unstable job (Dionne, 2007).

One may argue that spontaneous recovery accounts for pain relief and functional recovery. However, spontaneous recovery generally occurs after 2 - 3 weeks after the acute onset. Another question may arise as to whether the intervention is cost-effective. Our intervention seems to provide a positive answer, if we calculate the saving cost in sick leave, work slowing and a saving in painkiller cost with a decrease of diseases depending on their chronic use. The estimated cost saving of providing the extra service of a simple back program in UK ranged between 250 pound (367 US dollars, 300 euro) and 578 pound (850 US dollars, 694 euro) for each patient. The results indicate that the costs of this active back program are more than reimbursed as a consequence of earlier RTW (Wright, 2005). Although treatment programs are expensive, they can reduce pension expenditures, sick leave days, health care contacts, and pain (Bendix, 1996). Last but not least, we found that only $10 \%$ of those participants suffering from root compression at admission required surgical intervention ( $5 \%$ of the total sample of LBP). One of them was operated twice, a fact indicating possible adverse effects from surgical intervention. Thus, conservative treatment minimizes the risk of expensive surgical procedures. The majority of our participants (over 90\%) had RTW after few days from discharge without changes in the job settlement. Possible predictive factors from a backward selection procedure are: self-predicted timing of RTW, pain intensity, job satisfaction, social support, pain radiation, expectations of treatment success of the occupational physician. Demographic, work, LBP and psychosocial related factors improve the prediction of longterm sick-leave. The prediction should be always careful (Heymans, 2009). For a proper cost-benefit one should treat participants with musculoskeletal pain to the right level of intervenetion (Haldorsen, 2002). Quantitative information on the effect of ergonomic interventions on RTW leads to conclusion that intervention after 60 days, in the sub-acute phase of back pain, shows the most promising results (Elders, 2000).

The factors influencing RTW are related to the individual (such as age, education, pre-injury employment), the spine impairment and function, the environment (culture, legislation, services) and the workplace. Meta-analysis fail to show strong indications of efficacy, but their conclusions can be jeopardized by the different social milieu of Countries where observations were done. In our opinion, the generalization of results is limited by a political and financial context. This is particularly true for LBP. For example, even in our same Country, Italy, the treatment varies according to geographical areas, based on the availability of resources. Finally, we have to discuss the relatively lack of weight of the Job factor in our linear regression analysis. Class distinction between labourers and clerks is obsolete. Today, many labourers operate computers from a console to check the progress of industrial production. On the other hand, store clerks are often on their feet, lifting heavy weights 
and moving constantly.

\section{Conclusion}

There is moderate scientific evidence in Literature showing that multi-disciplinary rehabilitation, including a workplace visit or more comprehensive occupational health care interventions, helps RTW with fewer sick leaves and alleviates subjective disability. We have applied a multi-disciplinary model of intervention on 80 participants and observed a high rate of RTW, a reduction of painkiller medication, a low rate of surgical intervention and of relapses as well. Thus, our observations indicate that surgical operation is not the first choice of intervention, unless there is a severe spinal root impairment. A lesser usage of pain-killers prevents the side effects of medication and is beneficial for health-care financial resources. A cohort prospective design was applied. Further controlled studies are warranted for assessing the cost/benefit ratio. The clear prevalence of LBP in women recommends measures of preventing Medicine.

\section{REFERENCES}

Atroshi, I., Andersson, I. H., Gummesson, C., Leden, I., Odenbring, S., \& Ornstein, E. (2002). Primary care patients with musculoskeletal pain. Value of health-status and sense-of-coherence measures in predicting long-term work disability. Scandinavian Journal of Rheumatology, 31, 239-244. doi:10.1080/030097402320318440

Bekkering, G. E., Hendriks, H. J., van Tulder, M.W., Knol, D. L., Simmonds, M. J., Oostendorp, R. A., \& Bouter, L. M. (2005). Prognostic factors for low back pain in patients referred for physiotherapy, comparing outcomes and varying modelling techniques. Spine, 30, 1881-1886. doi:10.1097/01.brs.0000173901.64181.db

Bendix, A. F., Bendix, T., Vaegter, K., Lund, C., Frølund, L., \& Holm, L. (1996). Multidisciplinary intensive treatment for chronic low back pain, a randomized, prospective study. Cleveland Clinic Journal of Medicine, 63, 62-69.

Casso, G., Cachin, C., van Melle, G., \& Gerster, J. C. (2004). Return-to-work status 1 year after muscle reconditioning in chronic low back pain patients. Joint Bone Spine, 71, 136-139. doi:10.1016/S1297-319X(03)00059-9

Cohen, S. P., Argoff, C. E., \& Carragee, E. J. (2008). Management of low back pain. British Medical Journal, 337, a2718. doi: $10.1136 / \mathrm{bmj} . \mathrm{a} 2718$

Cole, M. H., \& Grimshaw, P. N. (2003). Low back pain and lifting, a review of epidemiology and aetiology. Work, 21, 173-184.

Croft, P. R., Macfarlane, G. J., Papageorgiou, A. C., Thomas, E., \& Silman, A. J. (1998). Outcome of low back pain in general practice, A prospective study. British Medical Journal, 316, 1356-1359. doi:10.1136/bmj.316.7141.1356

Demeurisse, G., Demol, O., \& Robaye, E. (1980). Motor evaluation in vascular hemiplegia. European Neurology, 19, 382-389. doi:10.1159/000115178

Deyo, R. A., \& Phillips, W. R. (1996). Low back pain a primary care challenge. Spine, 21, 760-765. doi:10.1097/00007632-199612150-00003

Deyo, R. A., Mirza, S. K., Turner, J. A., \& Martin, B. I. (2009). Overtreating chronic back pain, time to back off? Journal of the American Board of Family Medicine, 22, 62-68. doi:10.3122/jabfm.2009.01.080102

Dionne, C. E., Bourbonnais, R., Frémont, P., Rossignol, M., Stock, S. R., Nouwen, A., Larocque, I., \& Demers, E. (2007). Determinants of "return to work in good health" among workers with back pain who consult in primary care settings, a 2-year prospective study. European Spine Journal, 16, 641-655. doi:10.1007/s00586-006-0180-2

Ehrmann-Feldman, D., Rossignol, M., Abenhaim, L., \& Gobeille, D. (1996). Physician referral to physical therapy in a cohort of workers compensated for low back pain. Physical Therapy, 76, 150-156.

Elders, L. A., van der Beek, A. J., \& Burdorf, A. (2000). Return to work after sickness absence due to back disorders: A systematic review on intervention strategies. International Archives of Occupational and Environmental Health, 73, 339-348. doi: $10.1007 / \mathrm{s} 004200000127$

Fairbank, J. C. T., \& Pynsent, P. B. (2000). The oswestry disability index. Spine, 25, 2940-2953. doi:10.1097/00007632-200011150-00017

Ferreira, M. L., Ferreira, P. H., Latimer, J., Herbert, R. D., Hodges, P. W., Jennings, M. D., Maher, C. G., \& Refshauge, K. M. (2007). Comparison of general exercise, motor control exercise and spinal manipulative therapy for chronic low back pain: A randomized trial. Pain, 131, 31-37. doi:10.1016/j.pain.2006.12.008

Folstein, M. F., Folstein, S. E., \& McHugh, P. R. (1975). Mini mental state. A practical method for grading the cognitive state of patients for clinicians. Journal of Psychiatric Research, 12, 189-198. doi:10.1016/0022-3956(75)90026-6

Franchignoni, F. P., Tesio, L., Ricupero, C., \& Martino, M. T. (1997). Trunk control test as an early predictor of stroke rehabilitation outcome. Stroke, 28, 1382-1385. doi:10.1161/01.STR.28.7.1382

Frost, H., Lamb, S. E., \& Stewart-Brown, S. (2008). Responsiveness of a patient specific outcome measure compared with the Oswestry Disability Index v2.1 and Roland and Morris Disability Questionnaire for patients with subacute and chronic low back pain. Spine, 33, 2450-2457. doi:10.1097/BRS.0b013e31818916fd

Frymoyer, J. W. (1993). An international challenge to the diagnosis and treatment of disorders of the lumbar spine. Spine, 18, 2147-2252. doi:10.1097/00007632-199311000-00001

Giaquinto, S., Bruti, L., Dall'Armi, V., Gison, A., \& Palma, E. (2010). A bio-psycho-social approach for treating sub-acute low back pain. Disability \& Rehabilitation, 32, 1966-1971. doi: $10.3109 / 09638281003797349$

Gore, M., Sadosky, A, Stacey, B. R., Tai, K. S., \& Leslie D. (2012).The burden of chronic Low Back Pain, Clinical Comorbidities, Treatment Patterns, \& Healthcare Costs in Usual Care Settings. Spine (Phila Pa, 1976), 37, 668-677. doi:10.1097/BRS.0b013e318241e5de

Hagen, K. B., \& Thune, O. (1998). Work incapacity from low back pain in the general population. Spine, 23, 2091-2095. doi: 10.1097/00007632-199810010-00010

Haldorsen, E. M., Grasdal, A. L., Skouen, J. S., Risa A. E., Kronholm K., \& Ursin, H. (2002). Is there a right treatment for a particular patient group? Comparison of ordinary treatment, light multidisciplinary treatment, and extensive multidisciplinary treatment for long-term sick-listed employees with musculoskeletal pain. Pain, 95, 49-63. doi:10.1016/S0304-3959(01)00374-8

Hartvigsen, J., \& Christensen, K. (2008). Pain in the back and neck are with us until the end, a nationwide interview-based survey of Danish 100-year-olds. Spine, 33, 909-913. doi:10.1097/BRS.0b013e31816b45f1

Hayden, J. A., Van Tulder, M. W., Malmivaara, A, \& Koes, B. W. (2005). Exercise therapy for treatment of non-specific low back pain. Cochrane Database Systematic Reviews, CD000335. doi:10.1002/14651858.CD000335.pub2

Heneweer, H., Staes, F., Aufdemkampe, G., van Rijn, M., \& Vanhees, L. (2011). Physical activity and low back pain, a systematic review of recent literature. European Spine Journal, 20, 826-845. doi:10.1007/s00586-010-1680-7

Heymans, M. W., Anema, J. R., van Buuren, S., Knol, D. L., van Mechelen, W., \& de Vet, H. C. (2009). Return to work in a cohort of low back pain patients, development and validation of a clinical prediction rule. Journal of Occupational Rehabilitation, 19, 155-165. doi:10.1007/s10926-009-9166-3

Heymans, M. W., van Tulder, M. W., Esmail, R., Bombardier, C., \& Koes, B. W. (2005). Back schools for nonspecific low back pain, a systematic review within the framework of the Cochrane Collaboration Back Review Group. Spine, 30, 2153-2163. doi:10.1097/01.brs.0000182227.33627.15

Hoy, D., Brooks, P., Blyth, F., \& Buchbinder, R. (2010). The epidemiology of low back pain. Best Practice \& Research. Clinical Rheu- 
matology, 24, 769-81. doi:10.1016/j.berh.2010.10.002

Huskisson, E. C., Jones, J., \& Scott, P. J. (1976). Application of visual-analogue scales to the measurement of functional capacity. Rheumatology and Rehabilitation, 15, 185-187. doi:10.1093/rheumatology/15.3.185

Iles, R. A., Davidson, M., \& Taylor, N. F. (2008). Psychosocial predicttors of failure to return to work in non-chronic non-specific low back pain: A systematic review. Occupational and Environmental Medicine, 65, 507-517. doi:10.1136/oem.2007.036046

Indahl, A., Velund, L., \& Reikeraas, O. (1995). Good prognosis for low back pain when left untampered. A randomized clinical trial. Spine, 20, 473-477. doi:10.1097/00007632-199502001-00011

ISTAT (1999). Sistema Sanitario e salute della popolazione. Indicatori regionali. Rome: ISTAT Press.

Jensen, C., Jensen, O. K., Christiansen, D. H., \& Nielsen, C. V. (2011). One-year follow-up in employees sick-listed because of low back pain, randomized clinical trial comparing multidisciplinary and brief intervention. Spine, 36, 1180-1189. doi:10.1097/BRS.0b013e3181eba711

Jensen, I. B., Bergstrom, G., Ljungquist, T., \& Bodin, L. (2005). A 3-year follow-up of a multidisciplinary rehabilitation programme for back and neck pain. Pain, 115, 273-283. doi:10.1016/j.pain.2005.03.005

Jones, M., Edwards, I., \& Gifford, L. (2002). Conceptual models for implementing biopsychosocial theory in clinical practice. Manual Therapy, 7, 2-9. doi:10.1054/math.2001.0426

Juniper, M., Le, T. K., \& Mladsi, D. (2009). The epidemiology, economic burden, and pharmacological treatment of chronic low back pain in France, Germany, Italy, Spain and the UK, a literature-based. Expert Opinion on Pharmacotherapy, 10, 2581-292. doi: $10.1517 / 14656560903304063$

Karjalainen, K., Malmivaara, A., Mutanen, P., Roine, R., Hurri, H., \& Pohjolainen, T. (2004). Mini-intervention for subacute low back pain, two-year follow-up and modifiers of effectiveness. Spine, 29, 10691076. doi:10.1097/00007632-200405150-00004

Karjalainen, K., Malmivaara, A., van Tulder, M., Roine, R., Jauhiainen, M., Hurri, H., \& Koes, B. (2003). Multidisciplinary biopsychosocial rehabilitation for subacute low back pain among working age adults. Cochrane Database of Systematic Reviews, CD002193. 31.

Linn, B. S., Linn, M. W., \& Gurel, L. (1975). Cumulative Illness Rating Scale. Journal of the American Geriatric Society, 16, 622-626.

Linton, S. J., Boersma, K., Jansson, M., Overmeer, T., Lindblom, K., \& Vlaeyen, J. W. (2008). A randomized controlled trial of exposure in vivo for patients with spinal pain reporting fear of work-related activities. European Journal of Pain, 12, 722-730. doi:10.1016/j.ejpain.2007.11.001

Linton, S. J., Boersma, K., Jansson, M., Svärd, L., \& Botvalde, M. (2005). The effects of cognitive-behavioral and physical therapy preventive interventions on pain-related sick leave, a randomized controlled trial. The Clinical Journal of Pain, 21, 109-119. doi:10.1097/00002508-200503000-00001

Macedo, L. G., Maher, C. G., Latimer, J., \& McAuley, J. H. (2009). Motor control exercise for persistent, nonspecific low back pain. A systematic review. Physical Therapy, 89, 9-25. doi: $10.2522 / \mathrm{ptj} .20080103$

Macfarlane, G. J., Thomas, E., Papageorgiou, A. C., Croft, P. R., Jayson, M. I., \& Silman, A. J. (1997). Employment and physical work activities as predictors of future low back pain. Spine, 22, 1143-1149. doi:10.1097/00007632-199705150-00015

McGorry, R. W., Webster, B. S., Snook, S. H., \& Hsiang, S. M. (2000). The relation between pain intensity, disability, and the episodic nature of chronic and recurrent low back pain. Spine, 25, 834-841. doi:10.1097/00007632-200004010-00012

Moffett, J. K., Torgerson, D., Bell-Syer, S., Jackson, D., LlewlynPhillips, H., Farrin, A., \& Barber, J. (1999). Randomised controlled trial of exercise for low back pain, Clinical outcomes, costs, and preferences. British Medical Journal, 319, 279-283. doi:10.1136/bmj.319.7205.279

O’Sullivan, P. B., Phyty, G. D., Twomey, L. T., \& Allison, G. T. (1997). Evaluation of specific stabilizing exercise in the treatment of chronic low back pain with radiologic diagnosis of spondylolysis or spondy- lolisthesis. Spine, 22, 2959-2967. doi:10.1097/00007632-199712150-00020

Paassilta, P., Lohiniva, J., Goring, H. H., Perala, M., Raina, S. S., Karppinen, J., Hakala, M., Palm, T., Kröger, H., Kaitila, I., Vanharanta, H., Ott, J., \& Ala-Kokko, L. (2001). Identification of a novel common genetic risk factor for lumbar disease. JAMA, 285, 1843-1849. doi:10.1001/jama.285.14.1843

Reiso, H., Nygård, J. F., Jørgensen, G. S., Holanger, R., Soldal, D., \& Bruusgaard, D. (2003). Back to work, predictors of return to work among patients with back disorders certified as sick, a two-year follow-up study. Spine, 28, 1468-1473.

doi:10.1097/01.BRS.0000067089.83472.1F

Schonstein, E., Kenny, D. T., Keating, J., \& Koes, B. W. (2003). Work conditioning, work hardening and functional restoration for workers with back and neck pain. Cochrane Database Systematic Reviews, CD001822. doi:10.1002/14651858.CD001822

Selander, J., Marnetoft, S. U., Akerström, B., \& Asplund, R. (2005). Locus of control and regional differences in sickness absence in Sweden. Disability \& Rehabilitation, 27, 925-928. doi: $10.1080 / 09638280500030605$

Shaw, W. S., \& Huang, Y. H. (2005). Concerns and expectations about returning to work with low back pain, Identifying themes from focus groups and semi-structured interviews. Disability \& Rehabilitation, 27, 1269-1281. doi:10.1080/09638280500076269

Skouen, J. S., Grasdal, A. L., Haldorsen, E. M., \& Ursin, H. (2002). Relative cost-effectiveness of extensive and light multidisciplinary treatment programs versus treatment as usual for patients with chronic low back pain on long-term sick leave, randomized controlled study. Spine, 27, 901-909.

doi:10.1097/00007632-200205010-00002

Stapelfeldt, C. M., Christiansen, D. H., Jensen, O. K., Nielsen, C. V., Petersen, K. D., \& Jensen, C. (2011). Subgroup analyses on return to work in sick-listed employees with low back pain in a randomised trial comparing brief and multidisciplinary intervention. BMC Muscoloskeletal Disorders, 12, 112. doi:10.1186/1471-2474-12-112

Sullivan, M. J., \& Adams, H. (2010). Psychosocial treatment techniques to augment the impact of physiotherapy interventions for low back pain. Physiotherapy Canada, 62, 180-189. doi: $10.3138 /$ physio. 62.3 .180

Van Middelkoop, M., Rubinstein, S. M., Kuijpers, T., Verhagen, A. P., Ostelo, R., Koes, W. B., \& van Tulder, M. W. (2011). A systematic review on the effectiveness of physical and rehabilitation intervenetions for chronic non-specific low back pain. European Spine Journal, 20, 19-39. doi:10.1007/s00586-010-1518-3

Van Tulder, M. W., Koes, B. W., \& Bouter, L. M. (1995). A cost-ofillness study of back pain in The Netherlands. Pain, 62, 233-240. doi:10.1016/0304-3959(94)00272-G

Waddell, G. (2004) The back pain revolution. 2. Churchill Livingstone Edinburgh.

Westman, A., Linton, S. J., Theorell, T., Öhrvik, J., Wahlén, P., \& Leppert, J. (2006). Quality of life and maintenance of improvements after early multimodal rehabilitation. A 5-year follow-up. Disability \& Rehabilitation, 28, 437-446. doi:10.1080/09638280500192694

Wright, A., Lloyd-Davies, A., Williams, S., Ellis, R., \& Strike, P. (2005). Individual active treatment combined with group exercise for acute and subacute low back pain. Spine, 30, 1235-1241. doi:10.1097/01.brs.0000164266.00150.b6

Zampolini, M., Bernardinello, M., \& Tesio, L. (2007). RTW in back conditions. Disability \& Rehabilitation, 29, 1377-1385. doi: $10.1080 / 09638280701314980$ 